\title{
Components of Participatory Engagement within E-Learning Community
}

\author{
Noor Hida Natrah Aziz, Haryani Haron, Afdallyna Fathiyah Harun \\ Faculty of Computer \& Mathematical Sciences, Universiti Teknologi MARA, 40450 Shah Alam, Selangor, Malaysia
}

\begin{tabular}{l}
\hline \hline Article Info \\
\hline Article history: \\
Received Apr 9, 2018 \\
Revised May 20, 2018 \\
Accepted Jul 11, 2018 \\
\hline
\end{tabular}

\section{Keywords:}

Learners Engagement E-learning Community Participatory Engagement Learning

\begin{abstract}
This paper explores the components of participatory engagement to improve learner's engagement within the e-learning community. Data are gathered through observations to measuring the interactions of the learner's. The measurement included the learners' feedbacks through the interactions of learners and educators, learners and learners and learners and content. Follow-up interviews are conducted to get deeper insights into the interactions and overall learner's engagement environment. Findings show that in order to promote learners' engagement in e-learning components such as accessibility, mobility, active learning and collaboration must be present in an e-learning ecosystem.
\end{abstract}

Copyright () 2018 Institute of Advanced Engineering and Science. All rights reserved.

\section{Corresponding Author:}

Haryani Haron,

Faculty of Computer \& Mathematical Sciences,

Universiti Teknologi MARA,

40450 Shah Alam, Selangor, Malaysia.

Email: haryani@tmsk.uitm.edu.my

\section{INTRODUCTION}

Nowadays, it is common practice for educational institutions to use e-learning as an alternative learning approach. The vast development in ICT has changed the learning process from brick to click. Integration of ICTs in e-learning has transformed learning into several enhancement phases. In the first phase of learning, learners who have acquired knowledge are accessed through summative assessment. In the second phase, learner's interactions are limited; discussions are based on learning material, meanwhile, in the third phase of e-learning, learners are active participants through collaborative learning with other learners, leading to learner's empowerment on the learning process [1]. Other than that, the revolution of ICT has influenced concept e-learning to e-learning community for real interaction between participants, engage socially, active collaboration and solve the educational problem instantly.

ICT in e-learning bring positive impacts such as reduce participation gaps among learners, improve accessibility to learning resources, connecting with a wider range of participants. Learners have equal opportunities to access e-learning, sharing experience, enhance e-learners' interactions and encourage learners participation in various ways through different technologies. Thus, learners are more engaged with other learners in e-learning and experienced effective learning and improve learning satisfaction [2]. As the result, learners turn active learners, learning has become participatory and social, supportive of personal life goals and needs through socialization and collaboration with peers [3] and leads to engagement. Since elearning is becoming popular and trendier, continuous attention should be given on designing the instructional environment to improve learner's engagement is required. Term "engagement" is deemed to be essential to be inserted in e-learning to produce interactive interaction and learning as a place that learners prefer to learn. 
However, simply adopting e-learning does not guarantee engagement, improvement, and satisfaction without implementing the correct strategies. By placing learners at one place does not ensure learners will work collaboratively [1]. It is important for each group member to be sufficiently coordinated so that each one makes equal contributions to the success of the whole work. The current elearning ecosystem focuses on individualized asynchronous learning causing further seclusion [4]. Development of e-learning does not encourage and highlight on interactions among learners but focus on delivery content for designing experiences. Learning turns individually; without learners' participation, learning scopes are limited and an interaction is less interactive. Furthermore, conventional e-learning lacks participatory engagement which are co-learning and engagement [4]. In turn, participants are unable to engage well with learning activities and e-learning become a lonely, isolated space where the presences of others are rarely felt. Lacking interactions and communications in e-learning decrease learning motivation and supports from others. This is the factor leads to high dropout and e-learning successful rate is hard to achieve [5-6].

Previously, many research on e-learning but it are mainly focused on technologies and little attention given to learners' engagement within e-learning community. For instance, a platform for creating an optimal group in e-learning community focuses on solely on collaboration [1]. The element of collaboration itself in e-learning does not guarantee success learning and other elements must be inserting. Next, learning design structure integrated with pre-recorded video lectures, automated assignments, and quizzes with limited direct teaching interaction undertaken by the instructor [7]. Without interactions and communications in elearning, meaningful learning is hard to achieve. This paper focuses on the components of participatory engagement in e-learning community to supports learner's engagement process and types of activities that might improve learner's engagement in e-learning community.

\section{LITERATURE REVIEW}

\subsection{E-learning}

E-learning has the significant impact toward teaching and learning, thus e-learning has been implemented in most of the educational institutions. E-learning platforms take advantage of technologies to provide a better learning environment. Through e-learning, learners are able to learn and seek out knowledge which can be carried in and out of the classroom gives more choices in learning. Besides that, educators are able creates 'online courses, virtual seminars, and practical training' [8]. E-learning environment is connected to global network enable for learners and educators connected in own community. The virtual e-learning community opens up space for learners to form a group for discussing and interacting among them. As the result, e-learning community has become as an electronic space for learners seeking knowledge and develop the relationship in learning. In such an environment, the learners and the educators participate virtually through communicative technologies such as chats, forums or discussion boards [9]. E-learning community is a place for learners empowering their self and associated their self with rich information, heterogeneous entities; diversity from each other from the various backgrounds with the similar thought, interaction with members and learning and teaching together [10]. Engagement is undeniable as the most crucial elements in educations because it has positive implication in learning. Engagement is important to increase motivation, persistence in learning and more support form learner and teachers. Indirectly, the learners able to get moral and mental support from others and satisfied along learning process. Therefore, groups formed electronically this group are possible to develop friendship and relationships among participants.

\subsection{Participatory learning}

Participatory learning is grounded in John Dewey's idea that learners achieve better results if the learning process "reproduces, or runs parallel to, some form of work carried on in social life" [11]. Participatory learning can happen in two ways which are offline and online however this research is carrying out in an online environment. In an online learning context, participatory learning encourages learners to go beyond the educational institution, educators, and textbooks. E-learning creates a platform for learners to produce articulate information and contribute back to the community. Participatory learning environment involved of learning community, activities, and platform to execute. Previous researchers highlighted elearning platform support participatory learning community effectively [12-13]. In the participatory learning environment, learners are actively constructing their own new knowledge and deepen understanding through interaction with other learners within e-learning community [14]. Participations of learners in knowledge building promotes learners engagement whereby learners willingly taking part in group discussion and projects, sharing knowledge, working in a diverse way to share an interest and diverse interest from heterogonous participations and resources. Even though the learning is focused on learners, the presence of eeducator is compulsory. The role of e-educators as moderator or facilitator instead of teaching, for example, 
provides learning content, provide discussions subjects, motivates learners to participate in learning and provide feedback. E-educators encourage learners to actively involve in learning activities, stimulate learners thinking and share their own experience with others.

\section{METHODOLOGY}

This study is a qualitative approach and the paradigm of inquiry is interpretivist. The selected case study for this research is a public university at Universiti Teknologi MARA, Shah Alam. The selection of the case study based on preliminary study findings shows that selected case study has to employ most participatory engagement environment among five universities in Klang Area. This research used two techniques which are observations and interviews as data collection method. Observations are carried out for 12 weeks and data were collected during the learning process. The measurements used to identify participatory engagement are feedbacks and interactions of the learners to learners and educators to learners while using e-learning community.

Meanwhile, follow-up interviews are conducted to understand overall phenomena from respondents' perspective. The interview is a semi-structured interview and the questions were adapted from previous work [15]. The interview questions are divided into five categories which are a) demographic b) accessibility, c) interaction d) respond and e) interface. The in-depth interviews were carried out with 10 respondents. All respondents are selected randomly based on certain characteristics; learners in the participatory engagement environment and current learners who are experienced in participate in e-learning community. The respondents were chosen using snowballing techniques across any courses and semester. Out of 10 interviews, 7 interviews were conducted through face to face and 3 interviews were conducted through telephone-based. The interviews lasted between 30-40 minutes and were audio-recorded with permission and transcribed for analysis. The data were organized and analyzed using content analysis

\section{RESULT AND DISCUSSION}

In this section, the data collected were organized and coded into themes using content analysis as follows: Selecting relevant ideas, identifying repeated ideas, organizing the repeated ideas into themes and forming the narrative to describe the research questions. Based on data gathered, in e-learning ecosystem required (1) accessibility, (2) mobility, (3) active learning and (4) collaboration to enhance level of learners' engagement.

Table 1. Components of participatory engagement in e-learning community model

\begin{tabular}{|c|c|c|}
\hline $\begin{array}{c}\text { Participatory } \\
\text { engagement components }\end{array}$ & $\begin{array}{l}\text { Element of participatory } \\
\text { engagement } \\
\text { components }\end{array}$ & Technology detailed \\
\hline \multirow[t]{3}{*}{ Accessibility } & Flexibility & $\begin{array}{l}\text { E-learning community can be accessed regardless of geographical and } \\
\text { times conditions. }\end{array}$ \\
\hline & Self-paced & $\begin{array}{l}\text { Self- pace of studying when learning is based on learners' convenient } \\
\text { time. }\end{array}$ \\
\hline & Personalized learning & $\begin{array}{l}\text { Learners decide their learning styles such as types of learning, regulated } \\
\text { own learning content suited learners and types of devices to access e- } \\
\text { learning community. }\end{array}$ \\
\hline \multirow[t]{2}{*}{ Active learning } & $\begin{array}{l}\text { Two-way reciprocal } \\
\text { value }\end{array}$ & $\begin{array}{l}\text { Effective to supports feedbacks and two-way reciprocal interactions } \\
\text { between learners and educators. }\end{array}$ \\
\hline & Synchronous mode & Supports real-time interactions regardless of locations and time. \\
\hline \multirow[t]{2}{*}{ Mobility } & Mobile technology & $\begin{array}{l}\text { Mobile technology supports in accessing e-learning community at any } \\
\text { time and able to carry it anywhere. The learner can learn remotely } \\
\text { anytime. }\end{array}$ \\
\hline & Wireless technology & $\begin{array}{l}\text { Allowed to connect to mobile technology to internet and facilities } \\
\text { content repository and retrieve the learning content. }\end{array}$ \\
\hline Collaborative learning & Group based learning & $\begin{array}{l}\text { Able to form groups and facilitates learning regardless of locations and } \\
\text { together solve learning problems. }\end{array}$ \\
\hline
\end{tabular}

\subsection{Accessibility}

Accessibility in e-learning is essential component to improve learners' engagement in e-learning community that provides an opportunity to learn according to their convenience time and place. Accessibility in e-learning consists of three elements which are flexibility, self-pace and personalize learning. From the respondent responses, flexibility in e-learning reflects the access of e-learning platform. Accessibility of e- 
learning has facilitated respondents to easily obtained information, downloaded learning material, retrieved information and communications. Therefore, more respondents able to participate in learning activities to do discussion, quizzes, and downloading notes are done virtually. Respondents mentioned that e-learning has facilitated better learning process encourage more learners to participate in e-learning community without any limitations.

As working learners, the learners have limited time to study. E-learning platform offers self-paced learning whereby learners can access e-learning at their own convenient time to fulfil tasks and study. Learners lead their own learning such as choosing topics and how the durations to complete the tasks the topics. E-learning also supports personalized learning when learning is determined by respondents. Personalized learning gives respondents freedom to follow their own learning preference for example types of devices and material to study. Respondents are permitted to studying learning material is regulated by respondents' preferences and desires. Each learner has different learning time and flexibility, respondents have more power to choose own learning path. Respondents select any of provided learning material, learning devices and places to learn. Thus, component of accessibility in e-learning community able to enhance learners' willingness of participating in e-learning community.

\subsection{Mobility}

All respondents mentioned the important of mobile devices in daily life and especially in learning. A mobile device is a current trend and become a common way to access e-learning and has promoted mobility in e-learning. The usage of mobile technology in education has facilities faster interactions and feedbacks among respondents and has changed the way of respondents learn, interact, communicate and processing the knowledge improves engagement in e-learning community. Most of the respondents had the positive experience in access online learning platform via mobile devices. Undeniable, accessing online learning platform through mobile become a primary channel to deliver content.

Respondents choose to access e-learning through mobile devices because accessing e-learning become easier and faster. Respondents can check latest learning activity instantly and leads to frequent. Respondents who are working learners felt that learning through smartphone become efficient in uses of time. The popularity of using mobile devices are increased because ease of use and availability of wireless technology at most places has reduced learning distractions. Some of respondents the respondents indicated wireless technologies ease of uses and enjoyment has promoted the use of mobile devices in e-learning community. Respondents have valued mobility as one essential component to be integrated to improve learners' engagement in e-learning community.

\subsection{Active learning}

E-learning ensures quality in education since e-learning community provides active learning. Active learning is emphasising reciprocal value and synchronous interactions. Respondents mentioned that they able to learn positively through two ways interaction and reciprocal valued active to provide faster feedbacks. Feedbacks given by educators and learners deepened the understanding and learning felt that they from others views and thoughts. For instance, learners and educators given adequate feedback in clarify ideas, discussing ideas, and reflected and improved learning. Feedbacks in synchronous mode which is realinteractions are helpful in instant decision making. Respondents wants synchronous mode during learning process for a timely, comprehensive, and constructive and adequately feedback. Respondents mentioned that synchronous mode improves satisfaction and efficiency in time to communicate and all group members have to be there and commit toward group work. During the synchronous mode, respondents are not required to be at the same place to proceed learning. The constructive and informative feedback received has an impact on learner's participation. Respondents believe through participating in e-learning community has empower learners and leads to active learning. Active learning has turned the respondents from passive learner to active learners by being content provider. Respondents actively searching information, participate in the discussions, creates new ideas, expanded learning networking, take part in group discussion to improve the learning experience. This has empowered individual skills to be proactive and leads to real interactivity. In learning activities, learners are engaged in the learning process through group assignments, group discussions, and case studies. Respondents indicated interactions and communications among learners improve their learners' engagement.

\subsection{Collaborative learning}

The introduction of e-learning in educational institutions leads to better collaborative learning. Respondents believe that collaborative learning is beneficial and must have added to e-learning community. Collaborative learning is an active exchange of ideas within groups able to promote learners' engagement. Is overcomes isolation, promotes knowledge construction, facilitates group work, team working and ensure 
learners are actively communicating and interacting. For instance, a group-based activity promotes frequent interactions and communications among learners to accomplish group work and increase learners' interaction improves social connections and comprehends learners thinking. Respondents involved and mostly satisfy when learning through collaborative learning environment gives them a better output in learning within a limited time. Besides that, respondents agreed that collaboration is able to foster knowledge acquisition as exchange experience or ideas, exploring ideas on their own and to leads to a sense of belonging and socialization.

Respondents mentioned that they have learned faster through collaborative work to get more information and ideas from an experience learner in others perspective specific field. Collaboration work allows the exchange of ideas and provides numerous pattern of interaction to acquire new knowledge. Collaborative works supported by technologies in e-learning such as online discussions board, commenting, chats and email support asynchronous and synchronous interaction in e-learning. Collaborative learning via e-learning turns learning to be more productive through good rapport among group member, learners able to interact with others to express their ideas and opinions and creation of learning a community.

\section{CONCLUSION}

E-learning is the widely implemented at educational institutions, issues on how to improve learners' engagement in e-learning community is become imperative. Therefore, identifying the components of participatory engagement learning is an effort to promote learners' engagement within e-learning community. In order to improve engagement, learners preferred to learn in convenience and efficient time. The trend of usage of mobile devices has changed the way of learning whereby learning through mobile devices as one of way to improve learners engagement. Easy access to multiple of learning resources changed learners independency form educators to themselves and participate more in e-learning community and learning turns to active learning. ICT has connected the learners and learning turn into social approach and learners are preferred to collaborate with each other to produce new knowledge and understand learning. The identified components of participatory engagement learning are important to assisting learners frequently interacting with another learner through collaborating within e-learning community. Participatory engagement is expected to bring dynamic learning and bring more benefits in e-learning ecosystem as well as more participants into e-learning community.

The limitations of this research are the findings might not generalize beyond this study. This study focuses on tertiary learners thus the components of participatory engagement might be different in another learning environment. Besides that, the literature review is limited from 2013 until 2017 form several databases such as Elsevier, Science Direct, and IEEE. For further work, this research can be extended to empirical investigations with focusing on the possible use of technologies to support the components of participatory engagement learning. Another work is to investigate the platform that are able to support the components identified and implement in a real environment.

\section{REFERENCES}

[1] Maria-Iuliana D, Constanta NB \& Alexandru B. Platform for creating collaborative e-learning communities based on automated composition of learning groups. Engineering of Computer Based Systems (ECBS-EERC), 2013 3rd Eastern European Regional Conference on the IEEE.2013: 103-112

[2] Kuo Y.C. Interaction, Internet Self-Efficacy, And Self-Regulated Learning As Predictors Of Student Satisfaction In Distance Education Courses. Utah State University;2010

[3] McLoughlin C, Mark JWL. The Three P's of Pedagogy for the Networked Society: Personalization, Participation, and Productivity, International Journal of Teaching and Learning in Higher Education. 2008; 20(1):10-27

[4] Joharah A. Investigating role of interactivity in effectiveness of e-learning.PhD thesis. College of Engineering Design and Physical Sciences Department of Computer Science; 2

[5] Mourad, B., \& Karim, A. (2015). System Interactive Cyber Presence for E- Learning to Break Down Learner Isolation. International Journal of Computer Applications, 111(16), 35-40

[6] Walji, S., Deacon, A., Small, J., \& Czerniewicz, L. (2016). Learning through engagement: MOOCs as an emergent form of provision. Distance Education, 7919, 1-16.

[7] Gutl, C., Cheong, C., Cheong, F., Chang, V., Nau, S. Z., \& Pirker, J. (2015). Expectations of the generation NeXt in higher education: Learning engagement approaches in information sciences subjects. 2015 International Conference on Interactive Collaborative Learning (ICL), 205-214.

[8] Feldmann B.(2014) Two decades of e-learning in distance learning from web 1.0 to 2.0 at the University of Hagen. Learning technology for challenges, communication in computer and information science, vol.44(6),pp 163-173

[9] Taha Mansor, K. (2016). Web 2.0 technology: Social learning tools in higher education in Saudi Arabia. University Wollongong. 
[10] Haron.H, Aziz. NHN, Harun. A (2017) “A Conceptual Model Participatory Engagement Within E-learning Community. Procedia Computer Science, vol 116 p.p 242-250

[11] Marzano, G., Lubkina, Rezekne, and, \& Siguencia, L. O. (2016). Key Issues in Adult Non Formal Participatory ELearning. In International Scientific Conference (Vol. 4, pp. 69-79).

[12] Liu CC, Tseng KH \& Wu LY. A Participatory Learning Framework For Enhancing Children's Reading Experience With Electronic Book Readers. Research and Practice in Technology Enhanced Learning (RPTEL). 2017: 8(1);129151.

[13] Liaw, Marimuthu RA\& Idris M. Interactive challenges in Online Student Participatory Language Learning through Closed Social Network. Journal Creative Practise in Language Learning and Teaching (CPLT). 2014:2(2);27-37.

[14] Kujur, F., \& Singh, S. (2017).Engaging Customers Through Online Participation In Social Networking Sites. Asia Pacific Management Review, 22(1), 16-24.

[15] Ling, T. M., \& Harun, J. (2014). Instructional Scaffolding in Online Collaborative Learning Environment For Knowledge Construction Among Engineering Students. 2014 IEEE 6th International Conference on Engineering Education, 40-45. 